\title{
Article
}

\section{Using a dichoptic moving window presentation technique to investigate binocular advantages during reading}

Nikolova, Mirela, Jainta, Stephanie, Blythe, Hazel I. and Liversedge, Simon Paul

Available at https://clok.uclan.ac.uk/22338/

Nikolova, Mirela, Jainta, Stephanie, Blythe, Hazel I. and Liversedge, Simon Paul orcid iconORCID: 0000-0002-8579-8546 (2017) Using a dichoptic moving window presentation technique to investigate binocular advantages during reading. Journal of Experimental Psychology: Human Perception and Performance, 43 (2). pp. 265-280. ISSN 0096-1523

It is advisable to refer to the publisher's version if you intend to cite from the work. http://dx.doi.org/10.1037/xhp0000296

For more information about UCLan's research in this area go to

http://www.uclan.ac.uk/researchgroups/ and search for <name of research Group>.

For information about Research generally at UCLan please go to http://www.uclan.ac.uk/research/

All outputs in CLoK are protected by Intellectual Property Rights law, including Copyright law. Copyright, IPR and Moral Rights for the works on this site are retained by the individual authors and/or other copyright owners. Terms and conditions for use of this material are defined in the policies page. 
Using a dichoptic moving window presentation technique to investigate binocular advantages during reading

Mirela Nikolova* ${ }^{*}$, Stephanie Jainta ${ }^{2}$, Hazel I. Blythe ${ }^{3}$ and Simon P. Liversedge ${ }^{4}$

Affiliations:

1*: School of Psychology, University of Southampton, Highfield Campus, Southampton, SO17 1BJ, UK. Tel: 0044-23-80-595078, Email:

M.Nikolova@soton.ac.uk

2: IfADo - Leibniz Research Centre for Working Environment and Human Factors Ardeystrasse 67, D-44139 Dortmund, Germany. Tel: 0049-1084-272, Fax: 00491084401, Email: jainta@ifado.de

3 : School of Psychology, University of Southampton, Highfield Campus, Southampton SO17 1BJ, UK. Tel: 0044-23-8059-9399, Fax: 0044-23-8059-2606, Email:

hib@soton.ac.uk

4: School of Psychology, University of Southampton, Highfield Campus, Southampton SO17 1BJ, UK. Tel: 0044-23-8059-2917, Fax: 0044-23-8059-2606, Email:

S.P.Liversedge@soton.ac.uk

* Please address all correspondence to Mirela Nikolova, School of Psychology, University of Southampton, Highfield Capus, Southampton, S017 1BJ, Tel: 0044-2380-595078, Email: M.Nikolova@soton.ac.uk 
Abstract

Reading comes with a clear binocular advantage, expressed in shorter fixation times and fewer regressions in binocular relative to monocular visual presentations. Little is known, however, about whether the cost associated with monocular viewing derives primarily from the encoding of foveal information or in obtaining a preview benefit from upcoming parafoveal text. In the present sentence reading eye tracking experiment, we used a novel dichoptic binocular gaze-contingent moving window technique to selectively manipulate the amount of text made available to the reader both binocularly and monocularly in the fovea and parafovea on a fixation-by-fixation basis. This technique allowed us to quantify disruption to reading caused by prevention of binocular fusion during direct fixation of words and parafoveal preprocessing of upcoming text. Sentences were presented (1) binocularly; (2) monocularly; (3) with monocular text to the left of fixation (4) with monocular text to the right of fixation; or (5) with all words other than the fixated word presented binocularly. A robust binocular advantage occurred for average fixation duration and regressions. Also, while there was a limited cost associated with monocular foveal processing, the restriction of parafoveal processing to monocular information was particularly disruptive. The findings demonstrate the critical importance of a unified binocular input for the efficient pre-processing text to the right of fixation. 
Reading is a sophisticated uniquely human skill that requires the simultaneous operation and coordination of visual, oculomotor, attentional and linguistic processing systems. Recently, it has also been shown that binocular vision provides clear advantages for reading (Heller \& Radach, 1998; Jainta, Blythe, \& Liversedge, 2014; Jainta \& Jaschinski, 2012; Sheedy, Bailey, Buri, \& Bass, 1986). What is less clear, however, is how binocular vision and binocular coordination might influence foveal and parafoveal processing in reading, and, consequentially, what part they might play in the decision of where and when to move the eyes. In the present study, we address this issue by exploring how binocular advantages unfold throughout sentence reading, in relation to both parafoveal pre-processing as well as foveal processing of words. In the following sections, we describe the theoretical relevance of this work in relation to the influences of foveal and parafoveal information on oculomotor control decisions, the allocation of attention during reading, and the contribution of binocular coordination and binocular advantages to text processing prior to and during direct fixation. We then outline the design of a novel binocular dichoptic gaze-contingent eye tracking experiment, and explain how it allows the selective study of the influence of binocular vision processes during different stages of text comprehension.

\section{Oculomotor control and the allocation of attention during reading}

During reading, the eyes typically perform a sequence of fast ballistic movements known as saccades, which serve to direct the gaze from one word to another (i.e. version eye movements). Saccades are followed by brief periods of relative stillness known as fixations (200-300ms on average in reading), during which visual information is encoded (Raney, Campbell, \& Bovee, 2014; Rayner, 1998). These eye movements are a reflection of the ongoing cognitive processes underlying 
reading (Liversedge \& Findlay, 2000). To a very significant degree, the psychological processes related to visual and linguistic processing of text determine the two most important aspects of eye movement control in reading: when and where to move the eyes. A number of research findings have demonstrated that the availability of both foveal (directly fixated) and parafoveal (upcoming in the direction of reading) information is crucial for fluent reading, and that each type of information plays a distinct role in eye movement control (Rayner \& Pollatsek, 1987, 1989; Rayner, Pollatsek, Ashby \& Clifton, 2012). Characteristics of the foveal word such as its length, its lexical frequency, predictability from context and semantic compatibility with the preceding text influence the speed with which it is processed (i.e. fixation duration), and therefore the decision of when to move the eyes away from it and onto another word in the sentence (Ehrlich \& Rayner, 1986; Hyönä and Olson, 1995; Inhoff \& Rayner, 1986; Liversedge, Rayner, White, Vergilino-Perez, Findlay, \& Kentridge, 2004; Rayner \& Duffy, 1986; Rayner, Liversedge, \& White, 2006; Rayner, Liversedge, White, \& Vergilino-Perez, 2003; Rayner, Yang, Schuett, Slattery, 2014; White, 2008; see Hyönä, 2011 \& Rayner, 1998, for reviews). Interrupting foveal processing by visually degrading fixated words or masking them at fixation onset results in severe disruptions to reading, indicating the critical importance of a highquality visual input in the fovea for text comprehension (Fine \& Rubin, 1999; Legge, Ahn, Klitz, Luebker, 1997; Rayner, Inhoff, Morrison, Slowiaczek, \& Bertera, 1981).

When exploring the decision of where to move the eyes, it is important to first consider the allocation of attention during reading. Early research by McConkie and Rayner $(1975,1976)$ and Rayner (1975) examined the size of the perceptual span in reading, or the region from which readers obtain useful information during a fixation. This was done using the moving window paradigm, a gaze-contingent display change technique where a "window" of text with varying size is presented around the 
point of fixation and information beyond it is masked or visually degraded. The window moves on a fixation-by-fixation basis, so that equivalent amounts of unmasked text are available on each fixation. Many studies have found that, for readers of English and other alphabetic languages that are read from left to right, the effective visual field extends asymmetrically from 3-4 characters to the left of fixation (approximately the beginning of the fixated word) to 14-15 characters (approximately three words) to the right of fixation (Häikiö, Bertram, Hyönä \& Niemi, 2009; Rayner, 1986; Rayner, Castelhano, \& Yang, 2009; Schotter, Angele, \& Rayner, 2012). The notable asymmetry of the perceptual span indicates that for reading in English, as well as other languages with similar orthography, the critical parafoveal region from which most information is obtained is to the right of the fixated word (i.e. corresponding to the direction of reading). Experimental manipulations interfering with the availability of information in that region, such as reducing the number of visible characters or making the parafoveal word disappear after fixation onset on the preceding word, have been shown to cause considerable disruptions to fluent reading (Liversedge, et al., 2004; Rayner et al., 2006; Rayner, Liversedge et al., 2003; Rayner et al., 2014). This disruption is likely the result of the visual manipulation interfering with a reader's ability to pre-process parafoveal information to the right of fixation. Indeed, a number of studies have demonstrated that prior to directly fixating a word, readers are able to extract information about its length, orthographic and phonological features and use that information in order to direct their saccades (Juhasz, White, Liversedge, \& Rayner, 2008; McConkie \& Rayner, 1975; Pollatsek \& Rayner, 1982; Rayner \& Bertera, 1979). Furthermore, there is a robust preview benefit associated with uninterrupted parafoveal pre-processing. For example, when a word is masked or presented incorrectly in the parafovea, processing times for that word increase once it is directly fixated relative to when the 
correct version is available for pre-processing (Blanchard et al., 1989; Hyönä et al.; 2004; Rayner et al., 1982). Therefore, uninterrupted pre-processing of information to the right of fixation is a core characteristic of fluent reading, as it both guides the decision of where to move the eyes and aids word identification during direct fixation. In summary, both foveal and parafoveal information appear to play a key part in the decisions of when and where to move the eyes during reading, and these findings have been incorporated into the most influential models of oculomotor control during text processing (e.g., SWIFT, Engbert, Longtin, \& Kliegl, 2002; E-Z Reader, Reichle, 2011; Reichle, Rayner, \& Pollatsek, 2003).

\section{The role of binocular vision in reading}

Humans typically make use of both of their eyes when they read, and processes related to binocular coordination play a key role in providing a single, unified perceptual representation of written text. For most tasks at close viewing distances - including reading - high-precision binocular vision and a stable, single percept are attained via the process of fusion, which incorporates two integral components: motor and sensory fusion (Pratt-Johnson \& Tillson, 2001; Schor \& Tyler, 1981). Motor fusion comprises of the physiological mechanisms of vergence. A number of studies have revealed that during text processing, the two visual axes are often slightly misaligned by more than one character space (Blythe et al., 2006;

Blythe et al., 2010; Jainta, Hoormann, Kloke, \& Jaschinski, 2012; Liversedge et al., 2006a, Liversedge et al., 2006b, Nuthmann and Kliegl, 2009; Nuthmann, Beveridge, \& Shillcock, 2014; Vernet \& Kapoula, 2009). This is mainly due to transient divergence that occurs during saccades: the abducting eye typically makes a larger, faster movement than the adducting eye (Collewijn et al., 1988, Hendriks, 1996, Yang \& Kapoula, 2009; Zee et al., 1992). This divergence results in fixation disparity 
at fixation onset. Vergence eye movements (i.e. fine-grained oculomotor adjustments) are then made during fixations to counteract these disparities and to maximise the degree of correspondence between the two retinal inputs, even in reading (Jainta \& Jaschinski, 2012, Jainta et al., 2010; Leigh \& Zee, 2006). Sensory fusion - a neurophysiological and psychological process - serves to combine the two independent retinal representations into a single unified percept in the visual cortex as a basic step for further processing (Howard \& Rogers, 1995; Worth, 1921). Sensory fusion is only possible within a limited range of fixation disparities known as Panum's fusional area (Blythe et al., 2010; Schor et al., 1989; Steinman et al., 2000). Thus, for a large range of tasks including reading, motor fusion usually serves to reduce disparities and sensory fusion occurs when disparity falls within the functional fusional range (Jainta, Blythe, Nikolova, Jones, \& Liversedge, 2014).

The degree to which fixation disparity and processes underlying binocular fusion play a part in oculomotor control and the pre-processing of parafoveal text during reading has been investigated in a number of recent studies. For example, Nuthmann et al. (2014) used a binocular moving window technique to explore binocular coordination when only a limited amount of text was visible to the right of fixation (i.e. reading with a binocular moving window extending from 14 characters to the left of fixation to 2 characters to the right of fixation). They postulated that under this asymmetric window condition readers might be able to unconsciously increase the magnitude of their fixation disparity in order to make more parafoveal information available for processing. While Nuthmann and colleagues demonstrated that reading was considerably impaired when only two characters were available to the right of fixation, they found only limited support for their hypothesis with respect to binocular coordination. These findings suggest that binocular fusion processes during a fixation are not immediately affected by visual manipulations of parafoveal information. Note 
also that a further constraint with their methodological approach was that despite the use of a binocular moving window, the visual content that was available to both eyes during reading was very comparable. The lack of a dichoptic presentation method prevented the possibility of directly controlling the information that was exclusively available to one eye but not the other.

With respect to the limits of Panum's fusional area in reading, Blythe et al. (2010) conducted an experiment where participants were presented with stereoscopic linguistic stimuli (words or non-words) with varying degrees of horizontal disparity in a lexical decision task. The authors postulated that lexical identification and therefore accurate lexical decision - would only be possible if participants successfully fused the disparate stimuli (otherwise it would be impossible to distinguish between a word and a pronounceable non-word). The findings revealed that participants were able to make highly accurate lexical decisions when horizontal disparity was 0.37 deg of visual angle (approximately one character space), but when disparity increased to $0.74 \mathrm{deg}$ (two character spaces) performance was at chance. Furthermore, while appropriate vergence movements were made during the initial fixation on the stimulus in order to reduce the imposed stereoscopic disparity, no vergence adjustments were made during the initial saccade onto the stimulus. Thus, the authors concluded that the effective fusional range for linguistic stimuli corresponds to approximately one character space, and that participants did not use parafoveal binocular image disparity cues in order to coordinate binocular targeting of their saccades.

Another detailed exploration of binocular saccadic targeting was conducted by Liversedge et al. (2006). In their experiment participants read sentences with compound target words presented dichopticly, such that each eye received a 
separate independent input (e.g. if the target word was "cowboy", one eye only received the first half of the word "cowb" and the other eye only received the second half "wboy"; the remainder of the sentence was presented in full to both eyes). There were several possible ways in which saccadic targeting could operate under the experimental conditions: 1) each eye could target its own separate input, thereby suggesting independent, monocular control of saccades; 2) both eyes could target one of the word parts, thereby signifying suppression of one monocular input; 3) saccades could be targeted on the basis of the whole word, indicating that a unified percept was obtained prior to direct fixation. Indeed, the authors found that despite the dichoptic manipulation, saccadic targeting was identical to what is typically observed in normal reading: the eyes landed on the preferred viewing location (i.e. just left of the word center, Rayner, 1979; McConkie, Kerr, Reddix \& Zola, 1988) of the whole word. The results demonstrated that saccades in reading are targeted towards a unified percept of the parafoveal word that is derived at an early stage of processing, prior to direct fixation.

In summary, the above studies demonstrate the important role of binocular coordination and binocular fusion in parafoveal pre-processing prior to direct fixation. Interestingly, with respect to processing of the fixated word, Juhasz, Liversedge, White and Rayner (2006) found a degree of dissociation between binocular coordination processes during a fixation and the lexical characteristics of the fixated word. They found that during normal sentence reading, while fixation times on highfrequency (HF) words were shorter than fixation times on low-frequency (LF) words, fixation disparity did not differ systematically between the two conditions. Therefore, in normal reading conditions where binocular fusion is achieved without difficulty, foveal processing of a fixated word appears to be primarily influenced by the cognitive demands associated with that word. This is also the key assumption of 
180 influential computational models of oculomotor control in reading (e.g. E-Z Reader, 181 Pollatsek, Reichle, \& Rayner, 2006; Reichle, 2010; Reichle, 1998; Reichle, Rayner,\&

Pollatsek, 2003), which postulates that lexical processing is of primary importance in driving the forward movement of the eyes.

It is not clear, however, whether this is also the case when fusion is prevented, or when binocular information is not available. Binocular fusion is an important prerequisite for observing the advantages of binocular over monocular vision. For example, when visual input is binocular, luminance thresholds are lower and contrast sensitivities are higher (Blake \& Levinson, 1977; Campbell \& Green, 1965; Legge, 1984). Additionally, performance at orientation discrimination (Bearse \& Freeman, 1994) and letter recognition tasks is superior relative to when input is monocular (Eriksen et al., 1966). A number of studies have also provided evidence of global binocular advantages in a more complex task such as reading (Heller \& Radach, 1998; Jainta et al., 2014; Jainta \& Jaschinski, 2012; Sheedy et al., 1986). Binocular visual presentation results in faster reading speed as well as fewer fixations and regressions compared to monocular presentation. More importantly, a recent study by Jainta, Blythe and Liversedge (2014) demonstrated that binocular advantages are also present in lexical processing. The authors implemented an adaptation of the boundary paradigm (Rayner, 1975) in order to study the binocular advantages in reading. They placed an invisible boundary before a target word within a sentence and altered visual presentation from binocular to monocular or vice versa once a reader's eyes crossed the boundary. The target word was either a commonly occurring, easy to process, high-frequency (HF) word or a less common, more difficult, low-frequency (LF) word. The boundary manipulation created four visual presentation conditions for the target word: it could either be 1) previewed and fixated binocularly, 2) previewed and fixated monocularly, 3) previewed binocularly but 
fixated monocularly or 4) previewed monocularly but fixated binocularly. The authors found that the frequency effect on fixation times, which was present in binocular reading, was modulated in monocular reading, such that no significant differences were observed in processing times for high-frequency (HF) and low-frequency (LF) words. In addition, Jainta et al. (2014) observed a benefit of binocular relative to monocular text presentation in both parafoveal and foveal processing. That is, when a HF target word was monocularly presented in the parafovea but was fixated binocularly, or when direct fixation was monocular instead of binocular, processing of that word was slower relative to when binocular information was available either during preview or direct fixation. These findings provided a striking demonstration of the central role of binocular vision for efficient reading and word identification. What is less clear, however, is the extent to which binocular advantages for reading performance and word identification can be attributed entirely to the differences in binocular coordination (i.e. fixation disparity) when text is read with both eyes, relative to one eye.

\section{The present experiment}

In this context, the aim in the present study was to understand further the precise aspects of text processing that benefit from binocular vision, and to quantify the cost associated with monocular visual processing during encoding of both foveal and parafoveal words throughout sentence reading. We implemented a novel, dichoptic, gaze-contingent, moving window technique (McConkie \& Rayner, 1975), which allowed us to directly control the visual presentation of foveal and parafoveal text to each eye separately, on a fixation-by-fixation basis. We programmed a window of monocular text to either (1) move with the eye across the sentence or (2) dynamically increase or decrease in the parafovea to the left or to the right of fixation 
contingent on gaze position. Instead of using a window sized based on a fixed number of character spaces, we used word boundaries to define the margins of the moving windows. For instance, in order to pinpoint the cost of monocular foveal processing, we programmed the window such that when the eyes moved from one word in the sentence to the next, each fixated word was presented monocularly, and all the other words in the sentence were presented binocularly. In contrast, to quantify the cost of monocular parafoveal processing (either to the right or to the left), we presented each fixated word binocularly and all words either to the right or to the left of the fixated word, respectively, were presented monocularly. Thus, the number of words presented monocularly (i.e. the size of the monocular moving window) changed dynamically on a fixation-by-fixation basis, contingent on the position of the eyes within the sentence. These dichoptic moving window conditions were compared with pure binocular and pure monocular reading in order to exclusively investigate the binocular advantage associated with foveal and parafoveal processing. We analysed measures of global sentence processing and binocular coordination in order to explore the selective influence of our manipulation on reading performance and visual processing. We also embedded a target word manipulated for frequency in our sentences and investigated any potential modulations of the frequency effect that might occur in the different presentation conditions.

would cause considerable disruption to reading, which would be observed in sentence-level measures of eye movement behaviour, in binocular coordination measures (i.e. fixation disparity and vergence) and in target word processing measures (i.e. the frequency effect would be reduced if the target word was either previewed or fixated monocularly). Furthermore, we were interested in quantifying 
the cost of monocular foveal processing during reading relative to binocular foveal processing. Jainta et al. (2014) found that there was a substantial cost to the efficiency of lexical processing associated with monocular visual presentation when a word was directly fixated, even if that word had been previewed binocularly. We expected, therefore, a considerable level of processing difficulty to be associated with our gaze-contingent monocular presentation of the fixated word (relative to normal binocular viewing), with respect to global sentence processing, binocular coordination and target word identification. Finally, we investigated the cost associated with monocular input from the parafovea during sentence reading. Given previous findings that parafoveal monocular text causes impairment to reading, we predicted that a moving window in which words to the right of fixation were presented monocularly would affect global reading performance, even when, upon direct fixation, the word would be presented binocularly. Importantly, with relation to abovementioned findings regarding the asymmetry of the perceptual span, we predicted that the cost to processing at the sentence level would only be apparent, or at least would be far greater, when information to the right but not to the left of fixation was monocular.

\section{Method}

\section{Participants}

Participants were 20 native English speakers from the University of Southampton ( 6 males, 14 females, average age $=21.2$ years, range $=18-25$ years) . Participants took part in the experiment in exchange for Psychology course credits or payment at the rate of $£ 6$ per hour. All participants had normal or corrected to normal vision (with soft contact lenses) and no diagnosed reading difficulties. There were no substantial differences in acuity between the two eyes (best-corrected acuity in each 
280

281

282

283

eye was $20 / 20$ or better at $4 \mathrm{~m}$ ). Additionally, all participants had functional stereopsis (minimal stereoacuity of 40 seconds of arc). Participants were naïve to the purpose of the experiment.

\section{Apparatus}

Binocular eye movements were measured using two Fourward Technologies Dual Purkinje Image (DPI) eye trackers, which recorded the position of both eyes every millisecond (sampling rate of $1000 \mathrm{~Hz}$, spatial resolution $<1 \mathrm{~min}$ arc). Dichoptic presentation of the stimuli was achieved through use of Cambridge Research Systems FE1 shutter goggles, which blocked the visual input received by each eye alternatively every $8.33 \mathrm{~ms}$ (in synchrony with a $120 \mathrm{~Hz}$ refresh rate of the display monitor). The shutter goggles were interfaced with the eye trackers, a Pentium 4 computer and a Philips 21B582BH 21 inch monitor. The monitor was situated at a viewing distance of $100 \mathrm{~cm}$. To minimize head movements, participants leaned against two cushioned forehead rests and bit on an individually prepared bite bar.

Prior to the experiment, participants' visual acuity was tested both binocularly and separately for each eye using a Landolt- $C$ acuity chart and stereoacuity was tested using a Titmus Stereotest.

\section{Materials and design}

Forty sentences with neutral content were presented, as well as YES/NO comprehension questions after $25 \%$ of trials. Sentences were presented in 14 pt red uppercase/lowercase Courier New font on black background in order to minimise dichoptic cross-talk (i.e. the "bleed-through" of visual input to the occluded eye, see also Jaschinski, Jainta, \& Schurer, 2006). At the specified viewing distance, each letter subtended 0.25 deg of visual angle. On average, each sentence contained 
$76.63($ range $=72-86)$ characters. There were 12 words in each sentence, including a target word that was manipulated for lexical frequency. Target words were taken from the SUBTLEX-UK database (van Heuven, Mandera, Keuleers, \& Brysbaert, 2014) and mean frequency was calculated using Zipf values: 5.01 Zipf on average for HF words $(S D=0.48)$ and 2.05 Zipf on average for LF words $(S D=0.58)$. HF and LF target word pairs were matched on word length (mean target word length $=5.75$ characters). The words in each sentence were between four and eight characters long (mean word length $=6.38$ characters). The full list of stimuli is presented in Appendix 1. We divided the sentences into five blocks and presented each block of eight sentences in one of five dichoptic gaze-contingent presentation conditions: (1) All words in the sentence were binocular. (2) Each fixated word was monocular, but all other words were monocular. (3) Each fixated word was binocular but all words to the right of fixation were monocular. (4) Each fixated word was binocular but all words to the left of fixation were monocular. (5) All words in the sentence were monocular. The sentences were presented in 5 blocks of 8 sentences (each block in a different presentation condition). A Latin Square design was used and the presentation order of blocks in different conditions was counterbalanced, such that across all participants, each sentence appeared in each condition with each version of the target word, but no sentence was repeated for any individual participant, and each participant saw the blocks in a different order. Monocular presentations were counterbalanced across the left and right eye.

\section{Procedure}

The experimental procedure was approved by the University of Southampton Ethics and Research Governance Office and followed the conventions of the 
Declaration of Helsinki. Informed written consent was obtained from each participant prior to the start of the experiment.

After participants had agreed to take part in the experiment, tests of visual acuity and stereo-acuity were conducted. We used a monocular calibration procedure to calibrate the eye-trackers (i.e., the left eye was occluded by the shutter goggle during calibration of the right eye, and vice versa). Participants were instructed to look at each of nine points on a $3 \times 3$ grid in a set sequence from the top left to the bottom right. Horizontal separation of the calibration points was $10 \mathrm{deg}$, and the vertical separation was 2 deg relative to screen centre. Afterwards, the calibration was checked for accuracy and repeated if the Euclidian distance between the recorded eye position and the actual position of each validation point on the screen exceeded 0.06 deg of visual angle. Once both eyes had been calibrated successfully, participants completed five practice trials in order to get accustomed to the task and the experimental setup. At the end of the practice trials, a full calibration/validation run was completed once again and the experiment began.

Each trial consisted of the following sequence of events. A fixation circle appeared on the centre of the screen for $1500 \mathrm{~ms}$. Afterwards, another circle appeared on the left-hand side of the screen, marking the beginning of each sentence. Participants were required to fixate this circle. After $1000 \mathrm{~ms}$, the fixation circle disappeared and a sentence was presented. Once the participant had finished reading the sentence, they pressed a button on a button box to indicate that they had finished reading the sentence. Comprehension questions were presented after $25 \%$ of the sentences and participants used the button box to make a YES/NO response. The next trial was initiated by the button press at the end of the sentence, or the YES/NO response. Calibration was checked for accuracy after every 4 trials and the 
353

354

355

356

357

358

359

360

361

362

363

eye trackers were recalibrated if necessary. A full calibration/validation run was performed before each new block of 8 sentences was presented. Participants were given a break halfway through the experiment, as well as additional breaks whenever required. The entire procedure lasted for approximately 45-60 minutes.

\section{Data Analyses}

Custom-designed software was used for the data analyses. Fixations and saccades were manually identified in order to avoid contamination by dynamic overshoots (Deubel \& Bridgeman, 1995) or artefacts due to blinks. We excluded trials with track loss, fixations longer than $1200 \mathrm{~ms}$ or shorter than $80 \mathrm{~ms}$, as well as the first and the last fixation on each trial. The following analyses were conducted on the remaining $86 \%$ of data (8891 fixations).

From the separate signals of the two eyes, we calculated the horizontal and vertical conjugate eye components [(left eye + right eye)/2] and the horizontal and vertical disconjugate eye components [left eye - right eye]. For all the analyses of fixation disparity and vergence drift we only analysed fixations where the measured fixation disparity fell within 2.5 standard deviations of the mean for each participant in each condition ( $<1 \%$ of the data were excluded). Thus, we were able to exclude any atypically large fixation disparities (e.g., bigger than 2 deg), which may have occurred as a result of tracker error. At the same time, basing the exclusion criteria around the performance of each participant in each condition, we retained the typically larger fixation disparities observed in monocular reading due to increased divergence of the occluded eye.

We constructed Linear Mixed-effect Models (LMMs) using the Imer program from package Ime4 (version 1.1-11, Bates, Maechler, Bolker, \& Walker, 2014) in R, 
an open-source programming language and environment for statistical computation (R Development Core Team, 2012). Participants and items were included as random effects. We used the ImerTest package to compute $p$-values (Kuznetsova, Brockhoff, \& Christensen, 2016). Values for mean fixation duration, first fixation duration (FFD) and gaze duration (GD) were log-transformed prior to running the models due to the skewed right tails of their distributions. We report regression coefficients (bs), which estimate the effect size relative to the intercept, as well as standard errors (SEs) and $t$-values. Given the number of participants and observations per participant, the $t$-distribution will approximate the $z$-distribution; therefore we consider as statistically significant those cases where $|t|>1.96$ (Baayen, Davidson \& Bates, 2008). For binary dependent variables such as regression probability we used generalised linear mixed models (glmer function from package Ime4) and report the Wald $z$ and its associated $p$-value. All reported models were computed in the way that was most appropriate for our research questions. In each subsection, we first estimate binocular advantages in reading by comparing binocular and monocular presentation conditions. Because binocular reading represents the optimal condition for word processing and binocular coordination, we used it as baseline for all the models with a single predictor variable (i.e. presentation condition). We then estimated the specific cost of presenting foveal and parafoveal input monocularly relative to that baseline in order to establish whether binocular advantages are present during processing of text prior to or during direct fixation (or both). For models with interaction terms we computed successive difference contrasts using the contr.sdif function from the MASS package (Venables \& Ripley, 2002).

\section{Results}


Comprehension rate was at ceiling in all presentation conditions (mean

403

404

405

406

407

408

409

410

411

412 accuracy $=98 \%$ ). At the end of the experiment, we obtained subjective reports from each participant, asking about their visual experience. None of the participants were aware of the experimental manipulations. In fact, often participants did not believe that they had been reading monocular text at all, and asked us to repeat the viewing conditions after the experiment was completed to demonstrate that visual input to one of their eyes had been partially or entirely blocked during $80 \%$ of the trials. They were very surprised when we did this. This is a strong demonstration that in our sample of participants with normal vision, there was no immediate difference in perceptual experience between a binocular and a monocular visual presentation.

Below we report measures of global sentence processing, binocular coordination, and target word processing. All reported models were computed in the most appropriate way for our research questions. In each subsection, we first estimated binocular advantages in reading by comparing binocular and monocular presentation conditions. Because binocular reading represents the optimal reference level for word processing and binocular coordination, we used it as baseline for all the models with a single predictor variable (i.e. presentation condition). We then estimated the specific cost of presenting foveal and parafoveal input monocularly relative to that baseline, rather than the grand mean, in order to establish whether the availability of binocular input is more critical for the processing of text prior to or during direct fixation (or both).

\section{Global sentence processing measures}

\subsection{Comparison between binocular and monocular presentation. When} comparing binocular and monocular reading, we successfully replicated previous findings of binocular advantages for language processing in global measures of eye 
427 movement behaviour (see Table 1). Total sentence reading times were considerably

428 shorter in binocular reading compared to monocular reading. Furthermore, monocular reading resulted in a significant increase in mean fixation duration, more fixations and more regressive saccades than in the binocular presentation condition.

These results indicate that monocular text presentation substantially impaired 432 reading.

1.2. Monocular foveal processing. For this portion of the analyses we compared the monocular foveal viewing condition with binocular and monocular reading. The results for global sentence processing revealed no difference in sentence reading times between binocular monocular foveal presentations. However, average fixation durations were longer in the monocular foveal condition compared to binocular reading $(b=0.02, \mathrm{SE}=0.02, t=1.35, p=.08)$ and were in fact not significantly different from monocular reading $(t<1)$. As for the remaining measures (total sentence reading time, number of fixations and regression probability), we found no difference between binocular reading and the monocular foveal condition. It appears that whilst there was clearly a cost associated with restricting foveal processing to monocular input on a fixation-by-fixation basis, this level of disruption was not as great as was the case when the entire sentence was presented monocularly.

\subsection{Monocular rightward parafoveal processing. When comparing the} monocular parafoveal presentation to the right of the fixated word with binocular reading, we found no differences in mean fixation duration or regression probability (Table 1). We did, however, find a significant increase in total sentence reading times when text to the right of fixation was monocular, relative to binocular reading $(b=$ $304.60, S E=129.30, t=2.34, p<.001)$. This increase in sentence reading time 
452 when text to the right of fixation was monocular was not significantly different from

453 that observed when the entire sentence was presented monocularly $(t<1)$.

454 Participants also made more fixations when parafoveal information to the right of

455 fixation was monocular, compared to binocular reading $(b=1.01, S E=0.41, t=2.49$,

$456 p=0.04)$. This increase was again not significantly different from the increase

457 observed in monocular reading $(t<1)$. These data clearly suggest that monocular

458 presentation of parafoveal words to the right of fixation caused a similar degree of

459 disruption to reading as when the entire sentence was presented monocularly.

1.4. Monocular leftward parafoveal processing. As a final step in the analysis,

we investigated whether the cost associated with restricting parafoveal processing to

monocular visual input was present exclusively when the direction of the gaze-

reading with monocular parafoveal text to the left of the fixated word against

binocular and monocular reading. We found that measures of global sentence processing did not differ significantly between this condition and binocular reading

467 (Table 1). ${ }^{1}$

\section{Binocular coordination measures}

\footnotetext{
${ }^{1}$ In order to rule out any potential practice effects, we also included trial order as a fixed effect in the LMEs. We found no effect of trial order for any of the reported measures (all ts $<1$ ), showing that the blocked design (compared to a random, trialby-trial design) did not induce additional effects across the sentence presentations within each block or interactions with reading conditions.
} 
470 Below we report findings regarding fixation disparity at the beginning and at the end 471 of fixations, as well as proportion of aligned, crossed and uncrossed fixations. In 472 accordance with previous research, aligned fixations were defined as those where 473 both fixation points were within one character of each other within a word; crossed 474 fixations were those where fixation disparity exceeded one character space and the 475 left eye fixated further to the right than the right eye (eso); and uncrossed were those 476 fixations where disparity exceeded one character space and the left eye was fixating 477 further to the left than the right eye (exo). Fixation disparity measures and model parameters are reported in Table 2.

\subsection{Comparison between binocular and monocular presentation. We} replicated previous results relating to vergence behaviour during binocular reading (see Table 2). The average magnitude of fixation disparity in the binocular condition was 0.23 deg at the start of fixations, which is less than a character space. By the end of fixations, that disparity was significantly reduced to $0.16 \mathrm{deg}$ ( $t=-29.92, p<$ $.001)$. Critically, the magnitude of fixation disparity was significantly larger in monocular relative to binocular reading both at the start and at the end of fixation, although we did observe a significant reduction in disparity from start to end of fixation in the monocular condition $(t=-13.41, p<.001)$. We also replicated previously reported patterns of fixation disparity during binocular reading at the beginning and at the end of fixations (Blythe et al., 2010, Blythe et al., 2006, Liversedge et al., 2006a, Liversedge et al., 2006b). Disparities in the majority of fixations were aligned. Out of the remaining fixations, the majority of fixation disparities were uncrossed, and a small proportion were crossed. During monocular reading a smaller proportion of fixations were aligned at the beginning of the fixation 
495

496

497

498

499

500

501

502

503

504

505

506

507

508

509

510

511

512

period than in binocular reading, with uncrossed disparities accounting for the majority of misaligned fixations (see Figure 1). Those differences in proportion of misaligned fixations between the binocular and monocular presentation condition were significant for the start $(b=.50, z=5.75, p<.001)$ but not for the end of the fixation period $(b=-0.06, z=-0.69, p=0.50)$, suggesting that readers were able to compensate for the substantial initial misalignment that occurred for monocular fixations.

Next, we were interested in how binocular coordination changed throughout each trial, both in the binocular and monocular control conditions and in the gazecontingent conditions. We therefore examined how the absolute magnitude of fixation disparity at the beginning of fixations changed as a function of fixation position within the sentence from left to right and whether this varied between experimental conditions. In our comparison between binocular and monocular reading (i.e. our baseline conditions), we found a significant main effect of position within the sentence $(b=0.01, S E=0.01, t=10.43, p<.001)$ and a significant interaction between position and viewing condition $(b=-0.01, \mathrm{SE}=0.01, t=-5.751, p$ $<.001)$. As is evident from Figure 2, while fixation disparity magnitude in the binocular presentation condition tended to increase as the eyes moved from left to right along the sentence, it did so to a considerably lesser extent when reading was monocular. Similar findings were reported by Heller and Radach (1999) and Jainta et al. (2010). These results suggest that binocular coordination processes differ considerably between monocular reading both during a single fixation period and throughout an entire sentence reading trial.

2.2. Monocular foveal processing. With regard to fixation disparity, the magnitude of fixation disparity did not differ between binocular and monocular foveal 
presentation (see Table 2). There were no differences in the overall pattern of fixation disparities between binocular reading and the monocular foveal condition at the start of the fixation period (see Figure 1); there was, however, a significantly larger proportion of aligned fixations $(b=0.76, z=2.09, p=.021)$ at the end of the fixation period in the monocular foveal condition. Further, there was a significant interaction between position within the sentence and visual presentation $(b=-0.01, S E=0.00, t$ $=-5.51, \mathrm{p}<.001)$. We found that an accumulation of fixation disparity occurred as readers moved from left to right, but the initial magnitude of disparity and the extent to which disparity increased was smaller than in binocular reading. This pattern differed considerably from monocular reading, indicating that although in the monocular foveal condition each fixated word was only presented to one of the eyes, binocular coordination processes remained efficient.

\subsection{Monocular rightward parafoveal processing. The findings regarding} fixation disparity were somewhat surprising. Firstly, when text to the right of fixation was monocular, the magnitude of fixation disparity was considerably reduced in comparison to binocular reading both at the start and at the end of the fixation period. Furthermore, when parafoveal information to the right was monocular, $72 \%$ of fixations were aligned at the start of the fixation period, which was a significantly larger proportion than fixations in binocular reading $(b=0.94, z=2.53, p=.002)$. By the end of the fixation period the proportion of aligned fixations increased to $82 \%$, which again was significantly different from binocular reading $(b=1.22, z=2.19, p=$ .012). Furthermore, there was a significant interaction between viewing condition and position within the sentence $(b=-0.01, S E=0.00, t=-3.724, p<.001)$, such that when text to the right of fixation was monocular, initial fixation disparity magnitude was smaller than in binocular reading, and an accumulation of disparity occurred to a lesser extent (see Figure 2). Note that in this condition, participants started reading 
546 the sentence while only the first word that itself was under direct fixation, was

547

presented binocularly, while all the other words in the sentence were presented monocularly. As the participants moved their eyes through the text, each newly fixated word was presented binocularly, until the final word of the sentence was fixated, at which point, all the words in the sentence appeared binocularly. Thus, despite the fact that different proportions of the sentence were available to both eyes on each fixation, binocular coordination processes were not impaired.

\subsection{Monocular leftward parafoveal processing. Binocular fixation disparity at} the start and at the end of fixations when text to the left of fixation was presented to only one of the eyes did not differ significantly from binocular reading (see Table 3) . The proportion of aligned and misaligned fixations also did not differ significantly between the two conditions (Figure 1). Interestingly, we found a significant effect of fixation position within the sentence on absolute disparity magnitude $(b=0.01, S E=$ $0.00, t=8.11, p<.001)$ and a significant interaction between fixation position and viewing condition $(b=-0.01, S E=0.00, t=-5.71, p=.005)$ : it is evident from Figure 2 that the increase in disparity magnitude as the eyes moved from left to right along the sentence was smaller when text to the left of fixation was monocular than in binocular reading. Note that in this dichoptic moving-window condition, when participants started reading a sentence all words aside from the fixated word were binocular. As participants moved their eyes through the text, words to the left of fixation were presented monocularly until only the final word in the sentence was binocular and all other words were monocular. This dynamic viewing situation, however, did not seem to interfere with efficient binocular coordination. 
Recall that each sentence contained a target word manipulated for lexical frequency. Below we report first fixation durations (FFD) and gaze durations (GD) on the target word, as well as the number of first-pass fixations and number of regressions into the target region. Observed means and standard deviations are presented in Table 3. To estimate the differences between our different presentation conditions for the target word, we fit separate LMMs which estimated the effect of lexical frequency (HF vs LF target word), viewing condition and the interaction between the two for the 4 dependent variables: FFD, GD, number of first-pass fixations and number of regressions into the target region (see Table 4).

\section{- INSERT TABLE 3 AND TABLE 4 ABOUT HERE -}

3.1. Comparison between binocular and monocular presentation. We found a significant main effect of lexical frequency in FFD and GD, though neither the effect of condition, nor the interaction between frequency and condition were significant. Similarly, we found that participants made more first-pass fixations on, and more regressions into LF than HF target words, but neither of those effects was modulated by presentation condition or the interaction between the two factors. These findings suggest that participants processed HF words faster than LF words in both binocular and the monocular presentation conditions. Nevertheless, Table 3 clearly shows a numerical reduction in the frequency effect in monocular relative to binocular reading: we observed a 20 ms reduction in the frequency effect in FFD and a 98 ms reduction in GD. These reductions in the frequency effect were not significant in FFD $(b=1.04$, $t=0.03, p=.98)$, but were significant in GD $(b=-112.89, t=-2.44, p=0.03)$. In other words, under monocular compared to binocular viewing conditions GD was increased for HF words relative to LF words. This pattern of effects is similar to that reported by Jainta et al. (2014). 
3.2. Monocular foveal processing. We found a significant effect of lexical frequency when foveal input was monocular in FFD and GD. Those effects did not differ from binocular reading $(t s<1)$. We did not find a significant effect of presentation condition or of the interaction between the two fixed factors. Similar to binocular reading, participants made more first-pass fixations and more regressions into the target region if the target was LF relative to HF, but neither effect was modulated by presentation condition or the interaction between the fixed effects (Table 4). In other words, when a target word was previewed binocularly but fixated monocularly, participants were able to process it as efficiently as they did in binocular reading.

3.3. Monocular rightward parafoveal processing. Similarly to the other conditions, we found a significant effect of lexical frequency in FFD and GD when text to the right of fixation was monocular. We also found an increase in the number of first-pass fixations and regressions into the target region for LF relative to HF target words. Neither of those effects was modulated by visual presentation, nor did we find an interaction between them. Finally, we explored whether participants were able to obtain a larger preview benefit if the target word was previewed binocularly rather than monocularly. We found no effect of preview condition in either FFD ( $b=$ $0.03, S E=0.05, t=0.53)$ or $\mathrm{GD}(b=0.06, S E=0.06, t=0.94)$, suggesting that previewing the word monocularly did not affect fixation times when the word was directly fixated binocularly.

3.4. Monocular leftward parafoveal processing. We found that the significant effect of lexical frequency in FFD, GD, number of first-pass fixations and regressions into the target region did not vary as a function of condition or of the interaction 
620

between the fixed effects (see Table 4). Thus, lexical processing when text to the left of fixation was monocular was not impaired by the visual presentation.

\section{Discussion}

The present research replicated previous findings of global binocular advantages in reading. Our results clearly demonstrate that when visual input is binocular, sentence processing is faster and readers make fewer, shorter fixations than when it is monocular. These findings are in accord with previous research (Heller \& Radach, 1999; Jainta et al., 2014; Jainta \& Jaschinski, 2012; Sheedy, Bailey, Buri, \& Bass, 1986) and provide a further demonstration of the importance of binocular vision for the delivery of high-quality visual information necessary for fluent and efficient reading.

We then explored whether the binocular advantages observed in reading could be attributed to more efficient encoding of foveal information for binocular viewing, or more effective pre-processing of parafoveal information in binocular relative to monocular presentation conditions. Previous findings by Jainta et al. (2014) suggested that while binocular visual input both prior to, and during direct fixation on a word facilitates lexical processing, this facilitation is less pronounced when the word is monocularly fixated. We hypothesized, therefore, that restricting visual input to monocular information on a fixation-by-fixation basis would also result in considerable disruption to reading. Our findings were partially, but not entirely, consistent. We only observed a limited cost to processing in the monocular foveal condition, expressed in slightly longer mean fixation durations compared to binocular reading. That decrease in processing speed for the fixated words did not result in robust effects for total sentence reading time, nor did it result in a significantly increased rate of fixations and regressions. Our findings suggest, therefore, that 
645 when each word in a sentence is previewed binocularly but fixated monocularly, reading can proceed comparatively efficiently, relative to when larger portions of the sentence are presented monocularly. Critically, our results indicate that the considerable disruption to reading observed in the majority of eye movement measures in the monocular presentation condition cannot be attributed solely to disruption associated with encoding of foveal information. Instead, our data demonstrate that binocular input plays a key part in the efficient pre-processing of information to the right of fixation. As reported above, reading time increases and readers make more fixations when only monocular information is available in the parafovea to the right. In other words, binocular vision was associated with marked advantages in parafoveal pre-processing of upcoming text. Note also that we observed no differences between binocular reading and reading when text to the left of fixation is monocular, indicating that reading performance only suffered when binocular visual input was denied in the direction of reading. This finding is in line with previous studies (Liversedge et al., 2004; Rayner et al., 2003, 2006; Rayner et al., 2013), which have demonstrated that the critical region from which readers obtain information during reading of English and other languages read from left to right is to the right of fixation. Importantly, our results do not imply that there is a functional difference between the binocular fusion processes in the right and left visual field. They suggest, instead, that because in English more attention is allocated to text to the right of fixation than to the left, and because processing demands associated with that text guide eye movements, the need for a high-quality unified binocular input is more pronounced in the pre-processing of that text prior to direct fixation.

It is possible that the qualitative difference between a binocular and a monocular parafoveal presentation is such that when parafoveal input is monocular, the perceptual span is reduced. That is, the amount of useful information that readers 
671 extract during a single fixation may be influenced by the quality of the visual input.

672 Although our experiment provides no direct evidence for this hypothesis, previous 673 research by Legge, Ahn, Klitz, and Luebker (1997) and Legge, Cheung, Yu, Cheung, 674 Lee and Owens (2007) has found that the visual span - the number of letters that 675 can be reliably identified during a single fixation - to the left and to the right of the 676 fixation point - varies as a function of certain stimulus characteristics, such as contrast. Alternative explanations, for example, that binocular visibility could yield higher visual acuity or facilitate inter-hemispheric transfer, are also plausible (though see Dehaene, Cohen, Sigman, \& Vinckier, 2005 for further discussion). Further work is needed to test these different alternatives and to explore any potential differences in the size of the perceptual span - or indeed the degree to which readers can obtain useful information from text to the right of fixation - during binocular and monocular reading. To summarise, the present experiment replicated previous findings of binocular advantages in reading and demonstrated that, while binocular vision is important for the encoding of foveal information during reading, it plays a critical part in the efficient pre-processing of information to the right of fixation.

Aside from global reading behaviour, we also investigated the effect of our dynamic, gaze-contingent manipulations on binocular coordination. First, we replicated previous findings of binocular coordination in normal reading. When visual input was binocular, participants made predominantly convergent vergence movements in order to reduce fixation disparity throughout the fixation period. Fixation disparities that exceeded one character space were predominantly uncrossed (exo) and a small proportion were crossed (eso). This pattern of results is compatible with existing research (Blythe et al., 2010; Blythe et al., 2006; Jainta \& Jaschinski, 2012; Jainta et al., 2009; Liversedge et al., 2006a, Liversedge et al., 
different pattern of results). It is important to note, though, that during monocular reading, the magnitude of fixation disparity at the beginning of fixation was larger than during binocular reading. Although we did observe some reduction throughout the fixation period, likely reflecting the adaptability of tonic vergence (Schor \& Horner, 1989), monocular fixations remained significantly more disparate than binocular fixations (see also Jainta \& Jaschinski, 2012). These findings are not surprising: under monocular viewing conditions, where a fusion stimulus is not present and there is no disparity feedback (open-loop), the occluded eye tends to diverge to a fusionfree vergence position termed the phoria (Howard \& Rogers, 1995; Steinman et al., 2000). As a result, the observed disparity between the eyes is larger than in the binocular condition, where a fusion stimulus is present on each fixation. Our data demonstrate, furthermore, that during binocular reading there is an accumulation of fixation disparity as the eyes move from left to right throughout a sentence but that accumulation is not sufficient to disrupt fusional processes and cause diplopia (see also Heller \& Radach, 1998; Nuthmann \& Kliegl, 2009). Jainta et al. (2010) explained that this disparity accumulation throughout sentence reading is affected by each individual's ability to compensate for saccadic disconjugacy. This was not the case in monocular reading, where the magnitude of fixation disparity was increased from the first fixation in the sentence and remained relatively unchanged as readers moved their eyes from left to right.

Out of all comparisons between the five viewing conditions, the most striking results with respect to binocular coordination emerged when text to the right of fixation was monocular. For this condition, there was a larger overall reduction in fixation disparity at the beginning and at the end of fixations than in binocular reading. In addition, a significantly smaller proportion of fixations in this condition had a disparity magnitude that exceeded one character space. Furthermore, the 
accumulation of disparity throughout the sentence, which was present in binocular reading, was significantly reduced when text to the right of fixation was monocular. Importantly, these effects were maintained even when we controlled for factors such as saccade amplitude, fixation duration and recalibration rate, all of which could potentially influence the magnitude of fixation disparity. These results do not lend support to theories suggesting that readers may be able to adaptively increase their fixation disparity in order to make more information available parafoveally (Nuthmann et al., 2014). It is possible that the dynamic characteristics of the visual presentation in our experiment affected binocular coordination. Recall that when text to the right of fixation was monocular, an increasing proportion of the sentence was presented binocularly during each forward fixation (i.e. while initially only the first word was binocular, more words to the left of fixation became binocular as the eyes moved from left to right). This continuous increase in the amount of binocular information available during each fixation may have resulted in a reduction in fixation disparity and an overall tighter coupling of the eyes. Another potential explanation for our findings may be related to binocular saccadic targeting. Recall that Liversedge et al. (2006a) established that saccades in reading are targeted towards a unified parafoveal percept achieved at an early stage of processing. Furthermore, Blythe et al. (2010) found that when a lexical stimulus was presented dichoptically with imposed horizontal binocular image disparity, participants targeted their saccades towards it on the basis of a unified - but not fused - percept (i.e. if a 6-letter word was presented in the parafovea with 2 characters of horizontal disparity, saccades towards it were programmed on the basis of an 8-letter stimulus). In other words, binocular image disparity in the parafovea did not trigger vergence movements or affect the coupling of the eyes during saccades, but only upon direct fixation. A monocular parafoveal preview, on the other hand, may provide a less ambiguous 
saccadic target than a binocular one, because it will not be affected by binocular image disparity by definition, since only one visual input will be available for parafoveal processing. It might have been the case, therefore, that in the present experiment a monocular preview to the right of fixation affected saccadic coupling, and this in turn caused the reduced transient divergence and a smaller magnitude of fixation disparity at fixation onset.

Critically, however, the present results allow for an important distinction to be made between reading performance and the efficiency of binocular coordination processes. Although presenting text to the right of fixation monocularly was as disruptive to reading as an entirely monocular visual presentation, there was no cost to binocular coordination. That is, in contrast to monocular reading, the vergence system operated with a high degree of efficiency when text to the right of fixation was monocular (but the fixated word was binocular). These results indicate that there is dissociation between binocular coordination processes and reading performance when text to the right of fixation is monocular.

It is worth noting that current implementations of computational models of eye movements during reading do not specify a role for binocular fusion processes, either during direction fixation or in parafoveal pre-processing (Engbert, et al., 2002; Reichle, 2011; Reichle et al., 2003). The present data set clearly demonstrates, however, that binocular coordination impacts upon fixation times in reading; for example, word reading times were inflated following a monocular preview of that word. In the context of models of eye movement control, information from both the fixated word and the next word in the sentence is processed during fixations on the current word. Parafoveal pre-processing of the next word in the sentence, prior to its direct fixation, is known to be a key component of skilled sentence reading, and is 
774 integrated in all major theoretical/ computational models of eye movements during reading (Engbert, et al., 2002; Reichle, 2011; Reichle et al., 2003). If such preprocessing is either eliminated or reduced, then reading suffers - the reader takes longer to identify the word once it is directly fixated. One potential explanation for the observed pattern of results is that the monocular input to the right of fixation makes it difficult to extract useful features such as, for example, orthographic information. In this way, the efficiency of parafoveal pre-processing may have been reduced for monocular viewing conditions, thus reducing preview benefit on direct fixation times for each word. This may be somewhat mitigated by the fact that the subsequent, direct fixation on each word is binocular and word identification can operate in its optimal capacity at that point. These examples (1) demonstrate that binocular coordination impacts upon fixation times and (2) offer a possible explanation, within the framework of current models of eye movement control in reading, for why such effects occur. Adaptation of these models to accommodate the growing body of research that demonstrates such effects would be useful.

As a final point of interest, we included a lexical frequency manipulation in our experiment in order to explore the effect of the different visual presentation conditions on word identification. Recall that Jainta et al. (2014) found that the robust frequency effect present in binocular reading was modulated when sentence presentation was monocular. Further, they observed an increase in the processing time for HF words when they appeared monocularly during either parafoveal preview or direct fixation. In contrast, the present study found a significant frequency effect across all presentation conditions. Nevertheless, when focusing only on purely binocular and purely monocular reading - the two conditions where visual presentation was identical across the two experiments - the pattern of our results is compatible with that reported by Jainta and colleagues. They found $44 \mathrm{~ms}$ frequency effect in FFD 
800

801

802

803

804

805

806

807

808

809

810

811

812

813

814

and a $45 \mathrm{~ms}$ effect in GD during binocular presentation. These effects were drastically reduced to $1 \mathrm{~ms}$ in FFD and $8 \mathrm{~ms}$ in GD during monocular reading. In the present experiment, we found a $48 \mathrm{~ms}$ frequency effect in FFD and a $174 \mathrm{~ms}$ effect in GD during binocular reading, which were reduced considerably in monocular reading (28 $\mathrm{ms}$ in FFD and $76 \mathrm{~ms}$ in GD). This reduction in the frequency effect from binocular to monocular viewing conditions was statistically significant in GD in the present study, implying that the efficiency of processing for HF words suffered when reading was monocular. Thus, our findings map onto the pattern reported in previous research and suggest that an uninterrupted binocular input is an important prerequisite for efficient lexical identification. The differences in findings between the two experiments could potentially be due to the fact that Jainta and colleagues used a modification of the boundary paradigm (Rayner, 1975) whereby crossing an invisible boundary around the centre of each sentence switched visual presentation from binocular to monocular or vice versa. In contrast, the present experiment employed a gaze-contingent technique whereby visual presentation changed continuously, on a fixation-by-fixation basis and varying proportions of the text were binocular/monocular on each fixation. Secondly, while Jainta et al. (2014) presented their stimuli in randomised order, the present study used a blocked design. Taken together, these factors may have allowed for some degree of adaptation to occur across trials, thus contributing to a significant frequency effect in all presentation conditions. Future experimental work is necessary to test this possibility.

In conclusion, the present research explores the role of binocular vision for uninterrupted sentence reading. We used a novel, dichoptic, moving window, binocular, gaze-contingent change presentation technique and found that restricting foveal word processing during direct fixation to a monocular visual input did not cause a considerable disruption to reading. Instead, reading performance suffered 
826 when parafoveal information to the right of fixation was presented monocularly.

827 These results indicate that binocular vision provides clear advantages for the pre-

828 processing of upcoming, parafoveal text. Our findings speak to the complex interplay

829 between the human visual system and the language comprehension system, which is 830 fundamental for efficient reading performance.

831 
833 Baayen, R.H., Davidson, D.J., \& Bates, D.M. (2008). Mixed-effect modelling with 834 crossed random effects for subjects and items. Journal of Memory and $835 \quad$ Language, 59, 390-412.

836 Barr, D.J., Levy, R., Scheepers, C., \& Tily, H.J. (2012). Random effects structure for confirmatory hypothesis testing: Keep it maximal. Journal of Memory and Language, 68, 255-278.

Bates, D., Maechler, M., Bolker, B., \& Walker, S. (2015). Fitting Linear Mixed-Effects Models Using Ime4. Journal of Statistical Software, 67(1), 1-48. doi:10.18637/jss.v067.i01.

842

Blake, R., \& Levinson, E., (1977). Spatial properties of binocular neurones in the human visual system. Experimental Brain Research, 27, 221-232.

Blythe, H. I., S. P. Liversedge, et al. (2010). The effective fusional range for words in a natural viewing situation. Vision Research, 50, 1559-1570.

Blythe, H.I., Liversedge, S.P., Joseph, H.S.S.L., White, S.J., Findlay, J.M., \& Rayner, K. (2006). The binocular co-ordination of eye movements during reading in children and adults. Vision Research, 46, 3898-3908.

Campbell, F. W, \& Green, D.G. (1965). Monocular versus binocular visual acuity. Nature, 208, 191-192. 
854 Collewijn, H., Erkelens, C. J., \& Steinman, R. M. (1988). Binocular coordination of

855

856

857

858

859

860

861

862

863

864

865

866

867

868

869

870

871

872

873

874

875

876 human horizontal saccadic eye movements. Journal of Physiology, 404, 157182

Deubel, H. \& B. Bridgeman (1995). Fourth Purkinje image signals reveal lens deviations and retinal image distortions during saccadic eye movements. Vision Research 35, 529-538.

Ehrlich, S. \& Rayner, K. (1981). Contextual effects on word perception and eye movements during reading. Journal of Verbal Learning and Verbal Behavior, 20, 641-655.

Engbert, R., Longtin, A., \& Kliegl, R. (2002). A dynamical model of saccade generation in reading based on spatially distributed lexical processing. Vision Research, 42, 621-636.

Eriksen, C. W., Greenspon, T. S., Lappin, J. S., \& Carlson, W. A. (1966). Binocular summation in the perception of form at brief durations. Perception and Psychophysics, 1, 415-419.

Fine, E. M., \& Rubin, G. S. (1999). Reading with central field loss: number of letters masked is more important than the size of the mask in degrees. Vision Research, 39(4), 747-756.

Heller, D. \& Radach, R. (1999). Eye movements in reading: are two eyes better than one? In W. Becker, H. Deubel, T. Mergner (Eds.), Current oculomotor research: Physiological and psychological aspects. New York: Plenum Press.

Hendricks, A. (1996). Vergence movements during fixations in reading. Acta Psychologica, 92, 131-151. 
877 Howard, I. P., \& Rogers, B. J. (1995). Binocular vision and stereopsis. New York: Oxford University Press.

879

880

881

882

883

884

885

886

887

888

889

890

891

892

893

894

895

Howard, I. P., \& Rogers, B. J. (2012). Perceiving in depth. Volume 2, Stereoscopic vision. Oxford: Oxford University Press.

Hyönä, J. (2011). Foveal and parafoveal processing during reading. In S. Liversedge, I. Gilchrist, and S. Everling (Eds.). Oxford handbook on eye movements (pp. 819-838). Oxford, UK: Oxford University Press.

Hyönä, J., \& Olson, R.K. (1995). Eye fixation patterns among dyslexic and normal readers: Effects of word length and word frequency. Journal of Experimental Psychology: Learning, Memory, and Cognition, 21, 1430-1440.

Inhoff, A.W., \& Rayner, K. (1986). Parafoveal word processing during eye fixations in reading: Effects of word frequency. Perception and Psychophysics, 40, 431439.

Jainta, S., Blythe, H.I., \& Liversedge, S.P. (2014). Binocular advantages in reading. Current Biology, 24, 526-530.

Jainta, S, Blythe, H.I., Nikolova, M., Jones, M.O., \& Liversedge, S.P. (2014). A comparative analysis of vertical and horizontal fixation disparity in sentence reading. Vision Research, 110, 118-127.

Jainta, S., Hoorman, J., Kloke, W. B., \& Jaschinski, W. (2010). Binocularity during reading fixations: Properties of the minimum fixation disparity. Vision Research, 50, 1775-1785. 
899 Jainta, S. \& Jaschinski, W. (2012). Individual differences in binocular coordination are

900

901

902

903

904

905

906

907

908

909

910

911

912

913

914

915

916

917

918

919

920 uncovered by directly comparing monocular and binocular reading conditions. Investigative Ophthalmology and Visual Sciences, 53, 5762-5769.

Jaschinski, W., Jainta, S., \& Schürer, M. (2006). Capture of visual direction in dynamic vergence is reduced with flashed monocular lines. Vision Research, 46 (16), 2608-2614.

Juhasz, B.J., Liversedge, S.P., White, S.J., Rayner, K. (2006). Binocular coordination of the eyes during reading: Word frequency and case alternation affect fixation duration but not binocular disparity. Quarterly Journal of Experimental Psychology, 59, 1614-1625.

Juhasz, B.J., White, S.J., Liversedge, S.P., \& Rayner, K. (2008). Eye movements and the use of parafoveal word length information in reading. Journal of Experimental Psychology: Human Perception and Performance, 34, 15601579.

Kuznetsova, A., Brockhoff, P.B., \& Christensen, R.H.B. (2016). ImerTest: Tests in linear mixed effects models. R package version 2.0-30. http://CRAN.Rproject.org/package=ImerTest

Legge, G.E. (1984). Binocular contrast summation. I. Detection and discrimination. Vision Research, 24, 373-383.

Legge, G.E., Ahn, S.J., Klitz, T.S. \& Luebker, A. (1997). Psychophysics of reading. XVI. The visual span in normal and low vision. Vision Research, 37, 19992010. 
921

922

923

924

925

926

927

928

929

930

931

932

933

934

935

936

937

938

939

940

941

942

943

Legge G.E., Cheung, S.H., Yu, D., Chung, S.T.L., Lee, H.W., Owens, D.P. (2007). The case for the visual span as a sensory bottleneck in reading. Journal of Vision, 7, 1-15.

Leigh, R. J. \& D. S. Zee (2006). The neurology of eye movements. New York, Oxford University Press.

Liversedge, S.P. \& Findlay, J.M. (2000). Eye movements reflect cognitive processes. Trends in Cognitive Science 4 (1), 6-14.

Liversedge, S.P., Rayner, K., White, S.J., Findlay, J.M., \& McSorley, E. (2006a). Binocular coordination of the eyes during reading. Current Biology, 16, 17261729.

Liversedge, S.P., Rayner, K., White, S.J., Vergilino-Perez, D., Findlay, J.M, \& Kentridge, R.W. (2004). Eye movements when reading disappearing text: Is there a gap effect in reading? Vision Research, 44 (10), 1013-1024.

Liversedge, S.P., White, S.J., Findlay, J.M., \& Rayner, K. (2006b). Binocular coordination of eye movements during reading. Vision Research, 46, 23632374.

McConkie, G.W., Kerr, P.W., Reddix, M.D., \& Zola, D. (1988). Eye movement control during reading: I. The location of initial fixations on words. Vision Research, 28 (10), 1107-1118.

McConkie, G. W., \& Rayner, K. (1975). The span of the effective stimulus during a fixation in reading. Perception \& Psychophysics, 17, 578-586

McConkie, G. W., \& Rayner, K. (1976). Asymmetry of the perceptual span in reading. Bulletin of the Psychonomic Society, 8, 365-368. 
944 Nuthmann, A., Beveridge, M. E. L., \& Shillcock, R. C. (2014). A binocular moving window technique to study the roles of the two eyes in reading. Visual Cognition, 22(3), 259-282.

Pratt-Johnson, J.A. \& Tillson, G. (2001). Management of strabismus and amblyopia: A practical guide. New York: Thieme.

R Development Core Team (2011). R: A language and environment forstatistical computing. R Foundation for Statistical Computing, Vienna: Austria.

Raney, G. E., Campbell S. J., Bovee J.C. (2014). Using eye movements to evaluate the cognitive processes involved in text comprehension. Journal of Visualized Experiments, 83,

Rayner, K. (1975). Perceptual span and peripheral cues in reading. Cognitive Psychology, 7 (1), 65-81

Rayner, K. (1998). Eye movements in reading and information processing: 20 years of research. Psychological Bulletin, 124 (3), 372-422.

Rayner, K., \& Bertera, J.H. (1979). Reading without a fovea. Science, 206 (4), 468469.

Rayner, K. \& Duffy, S.A. (1986). Lexical complexity and fixation times in reading: 
effects of word frequency, verb complexity, and lexical ambiguity. Memory \& Cognition, 14, 191-201.

Rayner, K., Inhoff, A.W., Morrison, R.E., Slowiaczek, M.L., \& Bertera,J.H. (1981). Masking of foveal and parafoveal vision during eyefixations in reading. Journal of Experimental Psychology: HumanPerception and Performance, 7, 167-179.

Rayner, K., Liversedge, S. P., \& White, S. J. (2006). Eye movements when reading disappearing text: The importance of the word to the right of fixation. Vision Research, 46 (3), 310-323.

Rayner, K., Liversedge, S. P., White, S. J., \& Vergilino-Perez, D. (2003). Reading disappearing text: Cognitive control of eye movements. Psychological Science, 14 (4), 385-388.

Rayner, K., Yang, J., Schuett, S., \& Slattery, T.J. (2014). The effect of foveal and parafoveal masks on the eye movements of older and younger readers. Psychology and Aging, 29 (2), 2015-212.

Reichle, E.D. (2011). Serial attention models of readind. In S. P. Liversedge, I. D. Gilchrist, and S. Everling (Eds.). Oxford handbook on eye movements (pp. 767-786). Oxford, UK: Oxford University Press.

Reichle, E.D., Rayner, K., \& Pollatsek, A. (2003). The E-Z Reader model of eye movement control in reading: Comparisons to other models. Behavioral and Brain Sciences, 26, 445-526.

Schor, C.M. \& Tyler, C.W. (1981). Spatio-temporal properties of Panum's fusional area. Vision Research, 21(5), 683-692. 
991

992

993

994

995

996

997

998

999

1000

1001

1002

1003

1004

1005

1006

1007

1008

1009

1010

1011

1012

Schor, C.M., Heckman, T., \& Tyler, C.W. (1989). Binocular fusion limits are independent of contrast, luminance gradient and component phases. Vision Research, 29, 837-847.

Schor, C., \& Horner, D. (1989). Adaptive disorders of accommodation and vergence in binocular dysfunction. Ophthalmic and Physiological Optics, 9(3), 264-268.

Sheedy J. E., Bailey I. L., Buri M., \& Bass E. (1986). Binocular vs. monocular task performance. American Journal of Optometry and Physiological Optics, 63, $839-846$.

Steinman, S. B., B. A. Steinman, \& Garzia, R.P. (2000). Foundations of binocular vision: A clinical perspective. New York: The MacGraw-Hill Companies.

White, S.J. (2008). Eye movement control during reading: Effects of word frequency and orthographic familiarity. Journal of Experimental Psychology: Human Perception and Performance, 34, 205-223.

Worth, C. (1921). Squint. Its causes, pathology and treatment. Philadelphia: Blakiston.

Venables, W. N. \& Ripley, B. D. (2002) Modern Applied Statistics with S. 4th Edition. Springer, New York.

Vernet, M. \& Z. Kapoula (2009). Binocular motor coordination during saccades and fixations while reading: A magnitude and time anaysis. Journal of Vision, 9 (7), $1-13$

Yang, Q. \& Z. Kapoula (2003). Binocular coordination of saccades at far and at near in children and in adults. Journal of Vision 3(8), 554-561. 
1013 Zee, D.S., Fitzgibbon, E.J., \& Optican, L.M. (1992). Saccade-vergence interactions in 1014 humans. Journal of Neurophysiology, 68 (5), 1624-1641.

1015

1016

1017

1018

1019 
Figures and Tables

a)

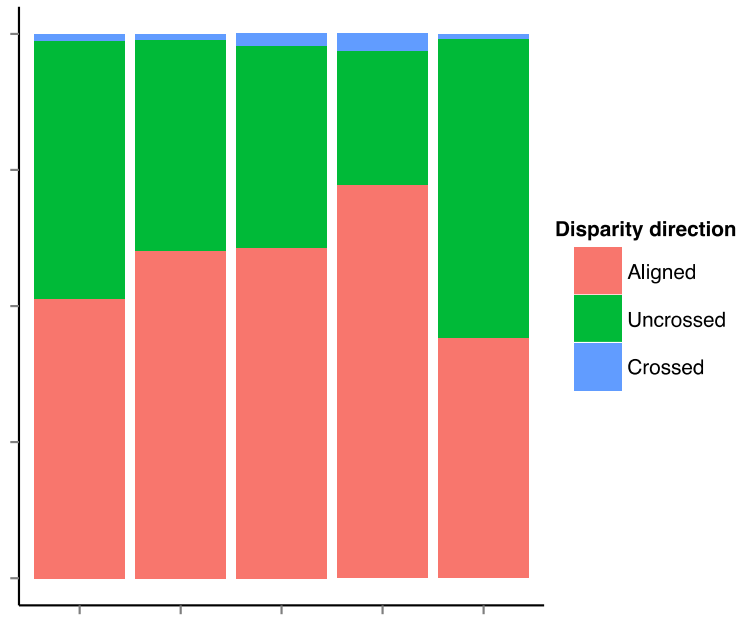

b)

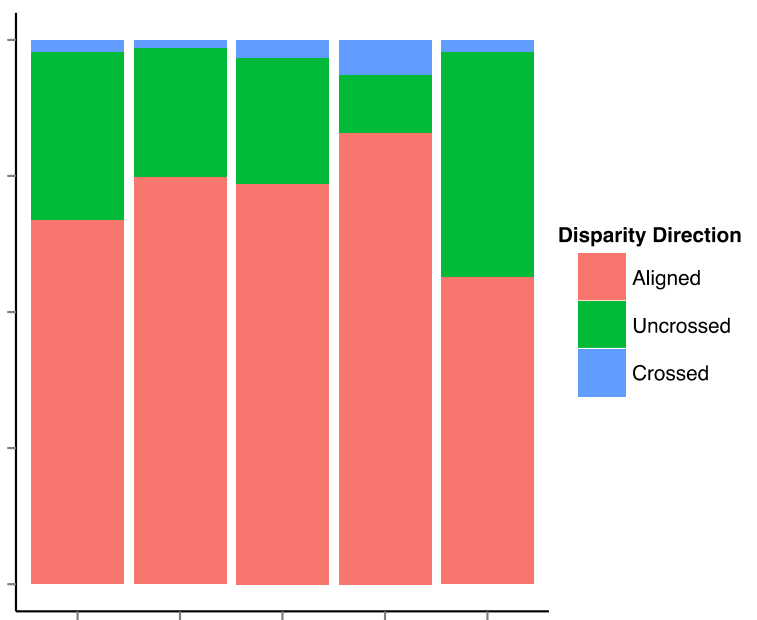

Figure 1. Proportion of aligned, uncrossed and crossed fixations across the different presentation conditions at the start (a) and at the end (b) of fixations. (1 Binocular; 2 - MF, 3 - MPL, 4 - MPR, 5 - Monocular). 
Figure 2. Interaction between fixation disparity at the beginning of fixations and the position of the eyes from left to right within the sentence.

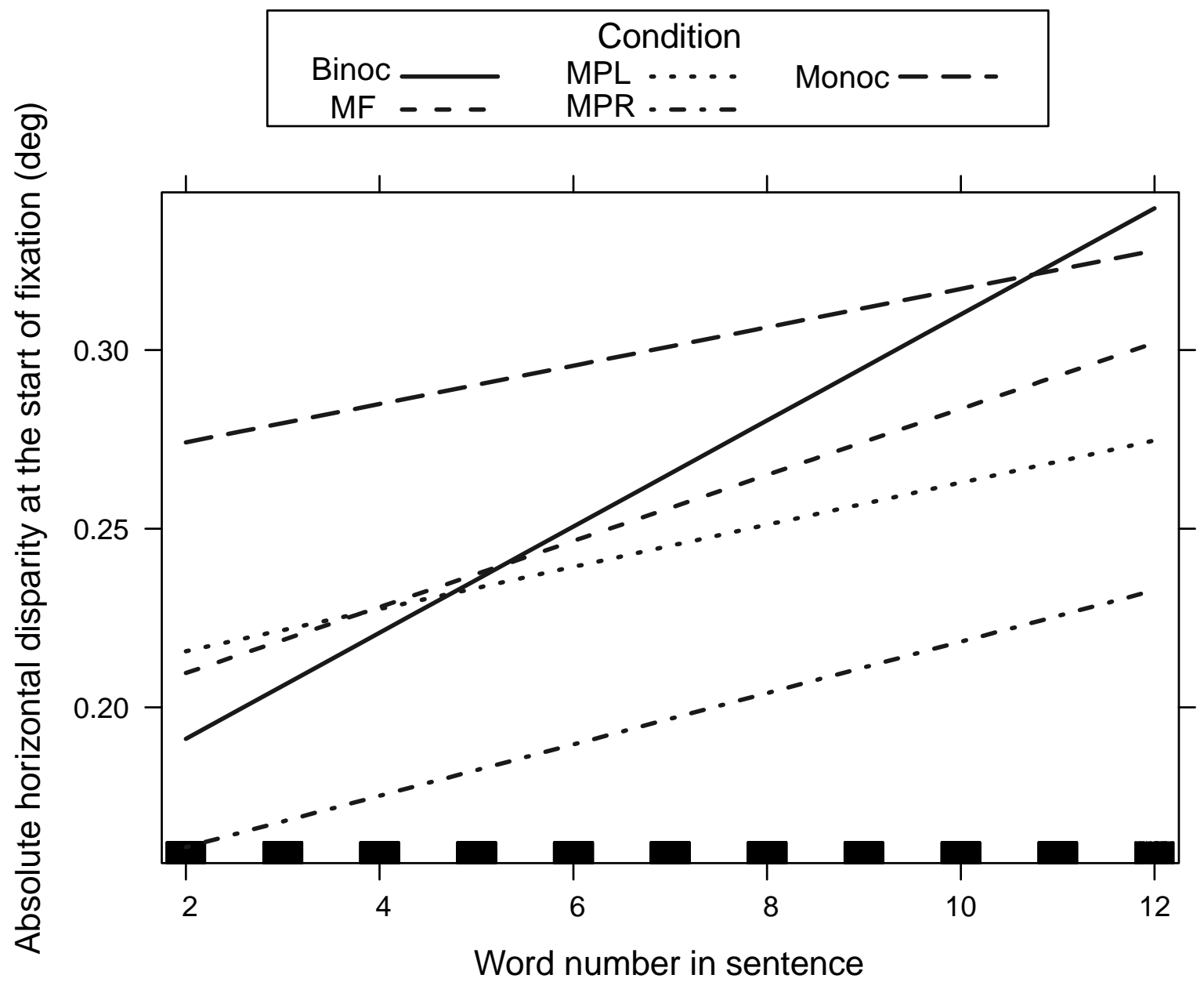

*Legend:

"Binoc" = binocular presentation of the entire sentence; "MF" = monocular presentation of the fixated word; "MPL" = monocular presentation of parafoveal text to the left of fixation; "MPR" $=$ monocular presentation of parafoveal text to the right of fixation; "Monoc" = monocular presentation of the entire sentence

The figure was plotted using the Effects library in $\mathrm{R}$, based on a model with the following structure: 
ModelName $=\operatorname{Imer}\left(D V \sim\right.$ Condition ${ }^{*}$ Position_In_Sentence +

(Condition*Position_In_Sentence/Participant) $+(1 /$ Item $)$, data = DataFile $)$ 
Table 1. Global measures of text processing.

\begin{tabular}{|c|c|c|c|c|c|c|}
\hline \multirow{2}{*}{$\begin{array}{c}\underline{\text { Variable name }} \\
\text { Mean fixation duration }\end{array}$} & \multicolumn{3}{|c|}{$\underline{\text { Model estimates }}$} & \multirow[b]{2}{*}{$p$} & \multicolumn{2}{|c|}{$\frac{\text { Observed descriptive }}{\underline{\text { values }}}$} \\
\hline & $b$ & $S E$ & $t$ & & Mean (ms) & $S D(\mathrm{~ms})$ \\
\hline Binocular (intercept) & 5.59 & 0.03 & 177.64 & $<.001$ & 289 & 118 \\
\hline Monocular Foveal & 0.04 & 0.02 & 2.34 & .03 & 298 & 115 \\
\hline $\begin{array}{l}\text { Monocular Parafoveal } \\
\text { Right }\end{array}$ & 0.02 & 0.02 & 1.20 & .97 & 287 & 115 \\
\hline $\begin{array}{l}\text { Monocular Parafoveal } \\
\text { Left }\end{array}$ & 0.00 & 0.02 & -0.26 & .15 & 291 & 109 \\
\hline Monocular & 0.06 & 0.01 & 3.29 & .001 & 306 & 117 \\
\hline $\begin{array}{l}\text { Total Sentence } \\
\text { Reading Time }\end{array}$ & $b$ & $S E$ & $t$ & $p$ & Mean (ms) & $S D(\mathrm{~ms})$ \\
\hline Binocular (intercept) & 3284.50 & 231.30 & 14.20 & $<.001$ & 3299 & 1249 \\
\hline Monocular Foveal & 195.50 & 153.21 & 1.28 & .12 & 3486 & 1310 \\
\hline $\begin{array}{l}\text { Monocular Parafoveal } \\
\text { Right }\end{array}$ & 304.60 & 129.30 & 2.34 & .002 & 3641 & 1329 \\
\hline $\begin{array}{l}\text { Monocular Parafoveal } \\
\text { Left }\end{array}$ & 207.90 & 152.90 & 1.36 & .16 & 3492 & 1434 \\
\hline Monocular & 443.30 & 171.10 & 6.73 & $<.001$ & 3813 & 1640 \\
\hline $\begin{array}{l}\text { Total Number of } \\
\text { Fixations }\end{array}$ & $b$ & $S E$ & $t$ & $p$ & Mean (ms) & $S D(\mathrm{~ms})$ \\
\hline Binocular (intercept) & 11.42 & 0.69 & 16.65 & $<.001$ & 11.4 & 4 \\
\hline Monocular Foveal & 0.33 & 0.48 & 0.70 & .44 & 11.71 & 4.07 \\
\hline $\begin{array}{l}\text { Monocular Parafoveal } \\
\text { Right }\end{array}$ & 1.01 & 0.41 & 2.49 & .04 & 12.53 & 5.03 \\
\hline $\begin{array}{l}\text { Monocular Parafoveal } \\
\text { Left }\end{array}$ & 0.78 & 0.54 & 1.49 & .15 & 12.33 & 4.54 \\
\hline Monocular & 0.98 & 0.43 & 2.27 & .004 & 12.46 & 4.79 \\
\hline Regression probability & $b$ & $S E$ & $z$ & $p$ & & \\
\hline Binocular (intercept) & -1.13 & 0.37 & -3.07 & $<.001$ & & - \\
\hline Monocular Foveal & 0.05 & 0.09 & 0.40 & .68 & & - \\
\hline $\begin{array}{l}\text { Monocular Parafoveal } \\
\text { Right }\end{array}$ & 0.14 & 0.09 & 1.54 & .12 & & - \\
\hline $\begin{array}{l}\text { Monocular Parafoveal } \\
\text { Left }\end{array}$ & 0.11 & 0.10 & 0.83 & .41 & & - \\
\hline Monocular & 0.20 & 0.10 & 2.11 & .03 & & - \\
\hline
\end{tabular}


* Each of the reported measures was entered as a dependent variable in a separate LME, with the following structure: Model.Name $=\operatorname{Imer}(D V \sim$ Condition $+($ Condition/Participant $)+$ (1/ltem), data $=$ DataFile). The model for regression probability was computed as follows: Model.Name $=$ glmer $(D V \sim$ Condition $+($ Condition/Participant $)+(1 /$ Item $)$, data $=$ DataFile, family = binomial) 
Table 2

Model estimates and descriptive values for fixation disparity at the beginning and at the end of each fixation, reported in degrees of visual angle.

\begin{tabular}{|c|c|c|c|c|c|c|}
\hline \multirow{2}{*}{$\begin{array}{l}\underline{\text { Variable }} \\
\text { Disparity } \\
\text { (start of } \\
\text { fixation) }\end{array}$} & \multicolumn{4}{|c|}{ Model Estimates } & \multicolumn{2}{|c|}{$\frac{\text { Observed descriptive }}{\underline{\text { values }}}$} \\
\hline & $b$ & $S E$ & $t$ & $p$ & |Mean| (deg) & $\begin{array}{l}|S D| \\
\text { (deg) }\end{array}$ \\
\hline $\begin{array}{l}\text { Binocular } \\
\text { (intercept) }\end{array}$ & -0.23 & 0.04 & 233.11 & $<.001$ & 0.25 & 0.16 \\
\hline MF & 0.01 & 0.01 & 1.00 & .86 & 0.25 & 0.22 \\
\hline MPR & 0.09 & 0.03 & 2.80 & .002 & 0.17 & 0.13 \\
\hline MPL & -0.04 & 0.04 & -1.10 & .42 & 0.23 & 0.17 \\
\hline Monocular & -0.09 & 0.05 & -2.00 & .001 & 0.31 & 0.20 \\
\hline $\begin{array}{l}\text { Disparity } \\
\text { (end of } \\
\text { fixation) }\end{array}$ & $b$ & $S E$ & $t$ & $p$ & |Mean| (deg) & $\begin{array}{l}|S D| \\
\text { (deg) }\end{array}$ \\
\hline $\begin{array}{l}\text { Binocular } \\
\text { (intercept) }\end{array}$ & -0.16 & 0.06 & 146.19 & $<.001$ & 0.18 & 0.15 \\
\hline MF & 0.01 & 0.01 & 0.86 & .82 & 0.19 & 0.20 \\
\hline MPR & 0.09 & 0.03 & 2.71 & .002 & 0.14 & 0.11 \\
\hline MPL & -0.02 & 0.08 & -0.26 & .41 & 0.18 & 0.15 \\
\hline Monocular & -0.11 & 0.05 & -2.02 & .004 & 0.24 & 0.18 \\
\hline
\end{tabular}

* "Binoc" = binocular presentation of the entire sentence; "MF" = monocular presentation of the fixated word; "MPL" = monocular presentation of parafoveal text to the left of fixation; "MPR" = monocular presentation of parafoveal text to the right of fixation; "Monoc" = monocular presentation of the entire sentence

${ }^{* *}$ Each of the reported measures was entered as a dependent variable in a separate LME, with the following structure: Model.Name $=\operatorname{Imer}(D V \sim$ Condition $+($ Condition $/$ Participant $)+$ (1/ltem), data = DataFile) 
Table 3.

Observed means $(S D)$ for measures of target word processing for high-frequency (HF) and low-frequency (LF) words.

* "Binoc" = binocular presentation of the entire sentence; "MF" = monocular presentation of the fixated word; "MPL" = monocular presentation of parafoveal text to the left of fixation; "MPR" = monocular presentation of parafoveal text to the right of fixation; "Monoc" = monocular presentation of the entire sentence

\begin{tabular}{|c|c|c|c|c|c|c|}
\hline \multirow[b]{2}{*}{ Variable } & \multirow[b]{2}{*}{ Frequency } & \multicolumn{5}{|c|}{ Condition } \\
\hline & & Binocular & $\underline{\mathrm{MF}}$ & MPR & $\underline{\mathrm{MPL}}$ & Monocular \\
\hline \multirow{2}{*}{$\begin{array}{l}\text { Regressions } \\
\text { into region }\end{array}$} & $\mathrm{HF}$ & $0.13(0.47)$ & $0.19(0.40)$ & $0.32(0.68)$ & $0.30(0.66)$ & $0.24(0.56)$ \\
\hline & LF & $0.69(0.90)$ & $0.48(0.68)$ & $0.45(1.08)$ & $0.76(0.71)$ & $0.94(1.60)$ \\
\hline \multirow{2}{*}{$\begin{array}{l}\text { Number of first } \\
\text { pass fixations }\end{array}$} & $\mathrm{HF}$ & $1.25(0.48)$ & $1.2(0.45)$ & $1.21(0.41)$ & $1.18(0.43)$ & $1.27(0.45)$ \\
\hline & LF & $1.62(0.90)$ & $1.47(0.89)$ & $1.46(0.76)$ & $1.47(0.78)$ & $1.40(0.63)$ \\
\hline \multirow{2}{*}{$\begin{array}{l}\text { First fixation } \\
\text { duration (ms) }\end{array}$} & $\mathrm{HF}$ & $289(121)$ & $284(85)$ & $284(91)$ & 275 (136) & 301 (105) \\
\hline & LF & 337 (120) & $342(138)$ & $320(128)$ & 333 (138) & 329 (159) \\
\hline \multirow{2}{*}{$\begin{array}{c}\text { Gaze duration } \\
(\mathrm{ms})\end{array}$} & $\mathrm{HF}$ & 352 (155) & 355 (230) & $344(146)$ & 331 (197) & 385 (197) \\
\hline & LF & $526(276)$ & $509(322)$ & $459(242)$ & $483(310)$ & $461(271)$ \\
\hline
\end{tabular}


Table 4. Model estimates for measures of target word processing.

\begin{tabular}{|c|c|c|c|c|c|c|c|c|c|c|c|c|c|c|c|c|}
\hline & \multicolumn{4}{|c|}{$\underline{\text { First fixation duration }}$} & \multicolumn{4}{|c|}{$\underline{\text { Gaze Duration }}$} & \multicolumn{4}{|c|}{$\frac{\text { Number of first-pass }}{\text { fixations }}$} & \multicolumn{4}{|c|}{$\frac{\text { Regressions into target }}{\text { region }}$} \\
\hline & $b$ & $S E$ & $t$ & $p$ & $b$ & $S E$ & $t$ & $p$ & $b$ & $S E$ & $t$ & $p$ & $b$ & $S E$ & $t$ & $p$ \\
\hline $\begin{array}{l}\text { Binocular } \\
\text { (intercept) }\end{array}$ & 5.67 & 0.05 & 104.01 & $<.001$ & 5.76 & 0.08 & 75.57 & $<.001$ & 1.38 & 0.06 & 23.89 & $<.001$ & 0.55 & 0.12 & 4.50 & $<.001$ \\
\hline Frequency (LF) & 0.14 & 0.05 & 2.90 & $<.001$ & 0.38 & 0.11 & 3.45 & $<.001$ & 0.25 & 0.09 & 2.80 & $<.001$ & 0.74 & 0.19 & 3.88 & $<.001$ \\
\hline $\begin{array}{l}\text { Presentation } \\
\text { (monoc) }\end{array}$ & 0.02 & 0.05 & 0.44 & .45 & 0.07 & 0.11 & 0.68 & .48 & 0.13 & 0.09 & -1.53 & .23 & 0.29 & 0.18 & 1.68 & .13 \\
\hline $\begin{array}{l}\text { Frequency } \mathrm{x} \\
\text { Presentation }\end{array}$ & 0.04 & 0.11 & -1.75 & .11 & 0.23 & 0.16 & -1.74 & .12 & 0.27 & 0.17 & -1.59 & .16 & 0.36 & 0.33 & 1.11 & .28 \\
\hline Frequency (MF) & 0.14 & 0.04 & 3.49 & $<.001$ & 0.39 & 0.11 & 3.49 & $<.001$ & 0.25 & 0.09 & 2.82 & $<.001$ & 0.60 & 0.14 & 4.40 & $<.001$ \\
\hline Presentation (MF) & 0.01 & 0.05 & 0.28 & 0.60 & 0.00 & 0.10 & 0.00 & .63 & 0.11 & 0.09 & -1.24 & 0.23 & 0.07 & 0.12 & 0.56 & .64 \\
\hline $\begin{array}{l}\text { Frequency } \mathrm{x} \\
\text { Presentation }\end{array}$ & 0.02 & 0.09 & 0.17 & .41 & 0.05 & 0.15 & -0.32 & .75 & 0.12 & 0.18 & -0.71 & 0.55 & 0.25 & 0.19 & 1.30 & .16 \\
\hline Frequency (MPR) & 0.12 & 0.04 & 2.95 & $<.001$ & 0.39 & 0.11 & 3.49 & $<.001$ & 0.25 & 0.08 & 2.96 & $<.001$ & 0.54 & 0.14 & 3.83 & $<.001$ \\
\hline $\begin{array}{l}\text { Presentation } \\
\text { (MPR) }\end{array}$ & 0.01 & 0.05 & -0.23 & 0.45 & 0.00 & 0.10 & 0.00 & .82 & $0 . \overline{11}$ & 0.08 & -1.31 & .23 & 0.03 & 0.12 & 0.26 & 0.89 \\
\hline $\begin{array}{l}\text { Frequency } \mathrm{x} \\
\text { Presentation }\end{array}$ & 0.07 & 0.09 & -0.72 & 0.35 & $\overline{-} 05$ & 0.15 & -0.32 & .19 & 0.15 & 0.16 & -0.90 & .49 & 0.21 & 0.20 & 1.54 & .14 \\
\hline Frequency (MPL) & 0.17 & 0.04 & 4.20 & $<.001$ & 0.30 & 0.06 & 5.05 & $<.001$ & 0.27 & 0.08 & 3.17 & $<.001$ & 0.64 & 0.16 & 4.06 & $<.001$ \\
\hline $\begin{array}{l}\text { Presentation } \\
\text { (MPL) }\end{array}$ & 0.02 & 0.05 & -0.48 & .47 & 0.10 & 0.06 & -1.61 & .54 & 0.13 & 0.08 & -1.61 & .19 & 0.12 & 0.13 & 0.96 & .38 \\
\hline $\begin{array}{l}\text { Frequency } \mathrm{x} \\
\text { Presentation }\end{array}$ & 0.09 & 0.09 & 0.91 & .31 & 0.01 & 0.13 & -0.09 & .39 & 0.10 & 0.16 & -0.62 & .43 & 0.09 & 0.24 & 0.37 & .88 \\
\hline
\end{tabular}


* Each of the reported measures was entered as a dependent variable in a separate LME, with the following structure: Model. Name $=\operatorname{Imer}\left(D V \sim\right.$ Condition ${ }^{\star}$ Frequency $+($ Condition + Frequency $($ Participant $)+(1 /$ Item $)$, data $=$ DataFile $)$ 
Appendix 1.

Experimental stimuli

1. Alice waters those exotic white flowers/orchids every five days during warmer months.

2. George always makes lovely fresh coffee/crepes when Jenny comes back from running.

3. Lizzie bought that purple silky dress/cloak while shopping with Laura last Friday.

4. When police officers went inside that large house/crypt, they found more clues.

5. Julie often drank tasty fresh orange/lychee juice during that long summer trip.

6. During cold months, Katie wears that yellow/pastel woollen scarf when walking outside.

7. During rugby games, fans always cheer/ovate when their team scores more points.

8. Those shallow lakes turned into thick nasty/fetid swamps after another long drought.

9. Roses were planted around father's garden/vinery years before those houses were built.

10. Those clever young thieves quickly/niftily covered their tracks before they were seen.

11. Anne never liked John's cousin, whose stupid/oafish remarks upset everyone last night.

12. Kings always fought with their loyal friends/vassals beside them, thus gaining power.

13. Some older liberal party members think/opine that civil laws need more changes.

14. Mary worried that extreme heat could damage/deform those rare delicate black pearls.

15. They feared their aunt's stern voice/glare, which always made them very nervous.

16. This business plan could bring/incur large costs unless someone offers expert advice.

17. After last night's party, Harry managed some broken/fitful sleep until sunrise came.

18. Jack could hardly hear Lilly's quiet/reedy voice after closing that heavy door.

19. Bold young cowboys often chase wild horses/dingos across those vast desert lands.

20. That small ship cruised along another river/fjord while tourists took more photos.

21 Their mother seemed very happy/jolly after finding those lost letters last night.

22. That greedy mayor made plans without thought/scruple about people from remote areas.

23. Alex would need better trading profit/acumen before opening another large bike shop.

24. Many people face this common problem/pitfall when changing their mobile phone number.

25. After that debate, Jake could never accept/recant other people's views about religion.

26. Their maths teacher would always explain/iterate complex rules until they were clear.

27. They never learned that critical story/axiom which affected their exam results poorly.

28. Locals often drink from those little/turbid streams, but tourists should avoid that. 
29. Anne's twin girls both have long black/mousy hair framing their round faces.

30. Track runners usually have strong/sinewy lean muscles after training for many years.

31. That famous French chef cooked/glazed fresh carrots, then served them with sauce.

32. They were driving through that lovely town/glen when their engine suddenly seized.

33. Linda knew that famous young doctor/sleuth because they studied together years ago.

34. While Alex finds those books very scary/vapid, John really loves reading them.

35. With that smile Kelly easily tricks/coaxes others into doing very boring work.

36. After coming home, they noticed some sweet/acrid smell coming from their kitchen.

37. Bill looked across that narrow field/chasm where several small houses once stood.

38. The young couple felt that their lunch/tryst could have been planned better.

39. Many ideas vary between different pagan groups/covens, often even among single members.

40. Many staff members will bother/accost John with questions after that budget meeting. 